\title{
Las Fuentes de las "Tradiciones Peruanas" de Ricardo Palma
}

\begin{abstract}
- AS Tradiciones peruanas presentan un vasto panorama de L la vida peruana del tiempo de los incas, y encierian, además de episodios incaicos, los sucesos memorables de la Conquista y la Colonia, la guerra de la Independencia nacional, y también los acontecimientos del siglo pasado durante la vida del distinguido autor. En consecuencia es evidente que la investigación completa de esta literatura, con el objeto de buscar sugerencias y determinar las fuentes que le sirvieron de inspiración, sería bastante extensa, ya que la inspiración del autor no pudo satisfacerse ni en una fuente, ni en un grupo de ellas.
\end{abstract}

Hay críticos que admiten que Palma, como tradicionalista, se sirvió de cuanta fuente utilizable le vino a la mano, de palabra o por escrito, y que pudiera darle el núcleo de una tradición. Pero la mayor parte de las opiniones expresadas con relación a las fuentes verdaderas no son más que conclusiones y suposiciones hechas después de haber leído los libros de Palma, o son comparaciones superficiales apoyadas en las declaraciones que hizo el mismo Palma.

A causa de la falta de un estudio que presente una identificación completa entre la obra de Palma y las fuentes de donde sacó la materia, nos pareció que valía la pena hacer tal estudio, con la esperanza de mostrar definitivamente cuanto se 
aprovechó él de los manuscritos de los cronistas, y de los documentos de la historia posterior. Lo que le causa asombro al investigador no es que Palma se fundase en los conceptos de los cronistas, sino que emplease frases, párrafos, y aun páginas enteras de ellos. Hay muchas pruebas de este hecho, y se puede dar página tras página de ejemplos.

Palma manifestó a menudo a sus lectores la fuente de donde sacó detalles y citas, pero los engañó de vez en cuando. Esto lo hizo en Carta canta, tradición del Perú colonial, cuando escribió en el prólogo: "Leyendo anoche al jesuíta Acosta... tropecé con una historia, y díjeme: Ya pareció aquella... cata el origen de la frasecilla en cuestión, para la cual voy a reclamar ante la Real Academia de la Lengua los honores de peruanismo". (1) Así nos hizo suponer que José Acosta, autor de la Historia natural y moral de las Indias, tuviera influencia en la formación de Carta canta, pero una lectura cuidadosa de la obra de Acostá no ofrece ninguna evidencia del asunto de la tradición.

Una situación muy al contrario aparece al contemplar los Comentarios reales de Garcilaso Inca de la Vega, que inspiraron un sinnúmero de tradiciones. iSe halla aquí el asunto completo de Caría canta casi en la forma idéntica que empleara Palma! Una casualidad significativa se nota además: antes de narrar el cuento, Garcilaso aludió a Acosta casi en la misma forma empleada siglos más tarde por Palma. ¿Sería la referencia de parte de Palma el resultado de haber sido descuidado cuando llamó a la memoria el cuento en su forma original, o sería posible que no quisiera dax, en esta ocasión, la fuente verdadera de donde sacó la tradición?

He aquí algunos trozos de la historia según la cuentan Palma y Garcilaso, los cuales darán un ejemplo de cómo toda la tradición sigue el relato de Garcilaso:

De Garcilaso:

El cual (el capataz) envió a su. amo diez melones, que llevaron dos indios acuestas, según la costumbre de ellos, con una carta.
De Palma:

El mayordomo escogió diez de los melones mejores... y los puso en hombros de dos indios mitayos, dándoles una carta. 
Ellos fueron su canino y... se descargaron para descansar. El uno dellos... dijo al otro: ¿No sabríamos a qué sabe esta fruta de la tierra de nuestro amo? El otro dijo, no, porque si comemos alguno, lo dirá esta carta... Replicó el primero, echemos la carta detrás de aquel paredón, y como no nos vea comer, no podrá decir nada.

Los Indios en aquellos principios, como no sabían qué eran letras, entendían que las cartas que los españoles se escribían unos a otros, eran como mensajeros... y que eran espías.

Queriendo los Indios proseguir su camino, el que llevaba los cinco melones... dijo al otro: No vamos acertados, conviene que emparejemos las cargas, porque si vos lleváis cuatro, y yo cinco, sospecharán.

Los ocho, que llevaban presentaron a su amo; el cual, habiendo leído la carta, les dijo: ¿qué son de dos melones, que faltan aquí? ... esta carta dice que os dieron diez y que os comisteis los dos. (2)
Habían avanzado los conductores algunas leguas, $\mathrm{y}$ sentáronse a descansar junto a una tapia. - $\mathbf{S a -}$ bes, hermano-dijo al fin uno de ellos-que he dado con la manera de que podamos comer sin que se descubra el caso? Escondamos la carta detrás de la tapia, que no viéndonos ella comer no podrá denunciarnos.

La sencilla ignorancia de los indios atribuía a la escritura un prestigio diabólico y maravilloso. Creían, no que las letras eran signos convencionales, sino espíritus, que no sólo funcionaban como mensajeros, sino también como... espías.

Cerca ya de Lima, el segundo mitayo se dió una palmada en la frente, diciendo: -Hermano, vamos errados. Conviene que igualemos las cargas; porque si tú llevas cuatro y yo cinco, nacerá alguna sospecha.

Llegados a casa de don Antonia pusieron en sus manos la carta... exclamó: -El mayordomo me manda diez melones, y aquí faltan dos. La carta dice que diez y ustedes se han comido dos por el camino. (3)

Entre los cronistas cuyos escritos utilizó Palma, predominó sobre todos Garcilaso de la Vega, y es claro que Palma sabía muy bien incorporar en sus Tradiciones las relaciones más a su propio estilo que encontró en los Comentarios reales. Entre las tradiciones que deben su origen a la inspiración de Garcilaso, quien, con su amenidad y gracia, hizo olvidar lo que escribieron los otros cronistas, pueden ponerse en lista La gruta de las maravillas, La achirana del Inca, El que pagó el pato, Quizá quiero, quizá no quiero, El verdugo real del Cuzco, 
Una partida de palitroques, El que se ahogó en poca agua, Carta canta, Una excomunión famosa, La fruta del cercado ajeno, Puesto en el burro. . . aguantar los azotes, y Un obispo de contrabando.

De los otros cronistas del Perú, Palma se refirió con mayor frecuencia a Fray Antonio de la Calancha, y en verdad sacó mucho de su Crónica moralizadora del Orden de San Agustín en el Perú. Esta influyó en la tradición La moda de los nombres de Pila y asimismo en Los panecitos de San Nicolás. En la última, Palma narró los mismos sucesos que relató Calancha, (4) pero llamó a su protagonista doña IMaría la Torre de Urdanivia, mientras que Calancha la llamó Ana de Escarcena. Sin embargo, Palma relató los sucesos en el mismo orden en que Calancha los puso. Lo de mayor significación es que Palma nos dió una prueba definitiva de que tomó la materia de esta fuente, por medio de una anotación hecha en el margen del ejemplar de la Crónica moralizada de la Biblioteca Nacional de Lima. En esta ocasión escribió "Gran milagro" al margen de la página que le dió el relato de Los panecitos de San Nicolás en su forma original. (5)

José Acosta, autor de la Historia natural y moral de las Indias, inspiró del mismo modo las tradiciones La mina de Santa Bárbara y Aceituna una, y contribuyó en parte a muchas otràs.

Palma mostró mayor fidelidad a las fuentes que inspiraron las tradiciones de los períodos antiguos, cuando se sirvió de las crónicas, que a las fuentes inspiradoras de las tradiciones que tratan de los siglos siguientes, para las cuales escogió ideas de varias fuentes incluyendo aun anécdotas de sus amigos, y noticias de los periódicos del día. Una base importante para las tradiciones de los días coloniales —además de las ya mencionadas- que no debe omitirse en este resumen, se encuentra en los Papeles varios de la Biblioteca Nacional. Palma se refirió a estos tomos repetidas veces, y le gustó tanto el Drama de los Palanganas, que escribió al principio del libro: "Este folleto es muy entretenido. Sobre las defraudaciones del virrey Amat al real tesoro y sobre su amancebamiento con Micaela Villegas, la Perricholi, hay pormenores 
curiosísimos que en mucho he utilizado para escribir una de mis tradiciones, titulada Genialidades de 1a Perricholi. Este folleto es una rareza bibliográfica, y se publicó en 1766, unos quince días antes de que llegara a Lima el señor Guirior en reemplazo de Amat, el cual consiguió recoger y quemar gran parte de la edición que fué de quinientos ejemplares y circulaba privadamente. R. Palma." (6)

En esta ocasión, no obstante, no siguió tan escrupulosamente la fuente como lo hacía con la crónica de Garcilaso; al contrario, cambió lo que tomó y lo revisó con espontaneidad, dejando perceptible, sin embargo, la narración original.

Cuando Palma halló un cuento escrito a su gusto y en estilo más o menos parecido al suyo, lo aceptó para una tradición, pero, al adaptarlo a la tradición, no menospreció de ningún modo su propio genio literario. Ejerció la misma libertad con relación a las citas de otros autores que incluyó en las tradiciones. Si el extracto le parecía demasiado largo o contenía porciones menos interesantes, lo recopilaba a la vez que hacía creer al lector que fuera exacto. AT fin y al cabo, hay que aceptar sus talentos extraordinarios y el hecho de que escribió las Tradiciones con el intento de presentar leyendas y anécdotas y no una historia puntualmente fidedigna, todo lo cual le permitió esta libertad de invención, sin aprensión de censura.

Muchos otros libros contribuyeron de una manera u otra a las Tradiciones, como Flor de academias y dienie del parnaso, de Juan de Caviedes, librito que se halla en la Biblioteca Nacional de Lima y que tuvo una ligera influencia sobre La emplazada y Cortar el revesino, pero verdaderamente influyó muy poco en la formación completa de estas tradiciones.

Aunque Palma empleó leyendas como fuentes para muchas tradiciones, también las estableció sobre bases de cierta precisión histórica, y en no menos de veinte ocasiones se refirió a Mendiburu y a su Diccionario histórico biográfico para la verificación de detalles. En La conspiración de capitanes introdujo a Mendiburu como uno de los protagonistas principales. 
El historiador Benjamín Vicuña Mackenna relató en $L a$ revolución de la independencia del Perú los episodios contados por Palma en El padre Pata y La custodia de Boqui, y hay un vestigio de su influencia en la tradición $D e$ cómo se casaban los oidores.

El suelo de Arequipa convertido en cielo, por D. Ventura Travada, nos da otro ejemplo más de la apropiación completa de una tesis para la estructura de una tradición. Esta vez resultó en El obispo del libro y la madre Monteagudo, tradición que trata de la venerable religiosa que pareció ser un verdadero oráculo en cuanto a sus profecías que siempre se cumplieron. Sacó Palma del libro de Traviada, sin cambiar excepto unas pocas palabras, la conversación de la madre Monteagudo, como sigue:

De Travada:

Verdad es que zozobró el bag'el en que se embarcó su ilustrísima; pero antes que se fuese a pique saltó en la barea con algunos compañeros, $\mathrm{y}$ arribando otra vez a Cádiz, volvió a embarcarse, y nam vega con favorable viento, $y$ presto pedirá corro para conducirse a esta ciudad. (7)

En otra ocasión:

\section{De Travada:}

No, hijos, no dice bien. El señor Almoguera es arzobispo de Lima, créanlo que es verdad y acuérdense de lo que digo. (9)

\section{De Palma:}

Pues yo digo que, aunque es cierto que zozobró el bajel, dió tiempo para que su ilustrísima salvase en la barquilla con unos pocos compañeros y llegase a la costa. Digo también que se ha vuelto a embarcar en Cádiz y navega con viento favorable. (8)

De esta manera toda la tradición imita la relación de Travada, y concluye con estas noticias acerca de la muerte de Almoguera :

\section{De Travada:}

Murió este ejemplar prelado de El nuevo arzobispo murió el 2 de Lima a 2 de marzo de 1676 de
Pues se equivoca, hijo mío, que el señor Almoguera arzobispo es ya de Lima. Créanlo, que es verdad, y acuérdense de lo que digo. (10) 
edad de setenta $y$ un años. $E 1$ mismo día que murió se apareció en Arequipa a la sierva de Dios la venerable Ana de los Angeles Monteagudo... Hijas mías... no veremos a nuestro obispo, ni su. Illma. nos verá a nosotras. (11) tenta y un años, y a la misma hora en que falleció daba en Arequipa la triste noticia la madre Ana de los Angeles Monteagudo... -iAy, hermanitas! No veremos a nuestro obispo ni él nos verá a nosotras. (12)

Las líneas citadas son ejemplos de los cuales existen muchos otros semejantes. De todos los críticos de las Tradiciones, nadie podía censurarle a Palma el haber incluído lo que leía con lo que escribía, porque era tan hábil en el arte de incorporar toda concepción para formular un conjunto intrínseco, que siempre predominó su personalidad individual.

Además de las tradiciones cuyas fuentes se establecen definitivamente, existen también las que deben su origen a un campo bastante grande. El retrato de Pizarro fué inspirada por William Hickling Prescott, el historiador americano. El cuento que se desarrolló en la tradición Orgullo de cacique, fué comunicado a Palma por un indio de Acarí con quien tropezó después del naufragio del vapor "Rimac". Inocente $G a-$ vilán, tradición del pexíodo de transición de colonia en república, nos trajo una experiencia de Palma mismo, en este caso una reunión con Gavilán, quien le delineó los detalles que formaron la tradición, siendo Gavilán uno de los protagonistas principales.

Durante el siglo de la independencia nacional, de 1825 en adelante, la vida y las experiencias de Palma sirvieron de fondo a la mayor parte de sus escritos. Palma era uno de los hombres mejor informados de su país respecto a los acaecimientos que se sucedieron durante el curso de su vida, aunque escribió en Los plañideros del siglo pasado: "Literariamente tengo la manía de vivir en el pasado. El ayer siempre es poético; es una especie del sol al que apenas se le ven manchas, porque está muy lejos". (13). ¿En qué fondo buscar mejor que en el de su propio sér para dar a las tradiciones de esta época los asuntos más vivos, más interesantes de todos? Al estudiar las tradiciones de esa época, vemos que Palma desempeña un papel en Los repulgos de San Benito, El godo $M a-$ 
roto, Entre Garibaldi... y yo, El baile de la victoria y La conga; conocía personalmente a las personas alrededor de las cuales tejió el asunto de María Abascal.

Dijo Palma de sus Tradiciones: "Mis amigos afirman que en cada pelo del bigote escondo una tradición, y ello debe ser cierto". (14) Esto es verdad especialmente en cuanto a las tradiciones que cuentan los hechos más recientes de la historia del Perú, país donde cada calle, cada balcón ofrecía algo de interés a nuestro autor, que él, con destreza sin igual, ensalzó y eternizó para todo el mundo de habla española.

En el curso de los siglos se forma gran cantidad de cuentos familiares y leyendas populares en todas las naciones, que mucho ofrecen al tradicionalista agraciado. Siempre que Palma tenía noticias de una leyenda rara, las apuntaba para usarlas en una tradición. Así pasó con La viudita y David y Goliath, que desarrollan leyendas populares de Arequipa. El alemán H. Petriconi ha afirmado que Palma tradujo no más la Legende von Hufeisen para formar Contra pereza diligencia, y la leyenda internacional conocida en Alemania con el título de Ulrich mit dem Buhel, escrita por Johann Musaus, para formar Salir con un domingo siete. (15) No ofrece Petriconi prueba de lo que dice, y no se puede encontrar base para la afirmación. Es posible que temas semejantes hayan procedido de una base común folklórica, pero una traducción del alemán, eso no.

La originalidad espontánea, el estilo brillante y gracioso y la enorme personalidad de Palma produjeron tradiciones que no tenían ni fuentes de leyendas ni bases históricas, sino concepciones imaginativas, fantásticas. Ricardo Rosell, su discípulo, dijo: "Con cuatro paliques, dos mentiras y una verdad, hilvana Palma una tradición". (16) De muchos paliques hilvanó Dónde y cómo el diablo perdió el poncho, La sandalia de Santo Tomás y Los siete pelos del diablo. Estas tuvieron sus raíces en la enérgica imaginación de Ricardo Palma, fuente más fecunda que todas las. crónicas, los libros históricos, las leyendas y los episodios cotidianos, y en la habilidad del famo- 
so tradicionalista para eternizar el alma peruana en la literatura del mundo.

\author{
Ruth Sievers Thomas, \\ Chico High School, \\ Cbico, California.
} p. 26 .

(1).-Palma, Ricardo, Tradiciones peruanas. Madrid, 1932, t. II,

(2).-Garcilaso Inca de la Vega, Primera parte de los comentarios reales. Madrid, 1723 , libro IX, cap. Xxix.

(3).-Tradiciones peruanas, t. II, pp. 28 y 29.

(4).-Calancha, fray Antonio de la, Crónica moralizada del Orden de San Agustin en el Perí. Barcelona, 1638. Libro I, cap. xxxxviii. Palma escribió en este libro: "Comprado el primer tomo para la Biblioteca de Lima en doce soles plata, Marzo 10 de 1890. R. Palma".

(5).-Crónica moralizada, p. 299. Palma tenía la costumbre de anotar los libros que leía. Siempre que encontraba una cosa que le agradaba, anotaba en los márgenes sus observaciones, y a menudo añadía la palabra "ojo" u otra frase pertinente.

(6).-Papeles varios de la Biblioteca Nacional. Lima, 1776, t. XXV.

(7).-Travada, D. Ventura, El suelo de Arequipa convertido en cielo. En Odriozola, Manuel D., Documentos literarios del Perí, Lima, 1877 , t. X, p. 140.

(8).-Tradiciones peruanas, t. III, p. 94.

(9).-El suelo de Arequipa, p. 144.

(10).-Tradiciones peruanas, t. III, p. 95.

(11). - El suelo de Arequipa, p. 148.

(12).-Tradiciones peruanas, t. III, p. 96.

(13).-Tradiciones peruanas, t. III, p. 226.

(14).-Tradiciones peruanas, t. III, p. 172.

(15).-H. Petriconi, Ricardo Palma, der Verfasser der Tradiciones peruanas. Revue Hispanique, t. LVII, pp. 207-285.

(16).- -Sociedad Amigos de Palma, Ricardo Palma, 1833-1933. Lima, 1934, p. 32. 
